\title{
Energy flexibility in Mediterranean buildings: a case-study in Sicily
}

\author{
Ilaria Marotta $^{1, *}$, Francesco Guarino ${ }^{1}$, Maurizio Cellura ${ }^{1}$, and Sonia Longo ${ }^{1}$ \\ ${ }^{1}$ Department of Engineering, University of Palermo, Viale Delle Scienze, Building 9, 90128 Palermo, \\ Italy
}

\begin{abstract}
Since the building sector is responsible for $40 \%$ of the world's electricity demand, it is essential to act on it in order to reduce emissions of climate change gases on a global scale, as expressed also in the latest directive on the energy performance of buildings. A design approach that focuses on the energy flexibility of buildings can contribute to the improvement of its energy-environmental performances. In this context, the objective of the study is the analysis of the energy performance of a residential building in Sicily and the definition of strategies aimed at increasing its energy flexibility. In particular, the case study is a $631 \mathrm{~m}^{2}$ single-family house, modeled and simulated in TRNSYS environment. The approach involves the development of scenarios to reduce operating costs and $\mathrm{CO}_{2}$ emissions during the use phase of the building. Rule Based Control algorithms are implemented. The flexible control reacts to a price or emission signal, by modulating the heating set-point accordingly. The results highlighted significant increases in energy flexibility. The economic algorithm achieves savings of $21.46 \%$, accompanied by a $15 \%$ reduction in emissions. The environmental algorithm allows to reduce $\mathrm{CO}_{2}$ emissions by about $30 \%$. The economic impact is positive, with a $17.58 \%$ reduction in costs.
\end{abstract}

\section{Introduction}

The building sector contributes about $40 \%$ of global electricity demand and $28 \%$ of energyrelated carbon dioxide emissions [1]. For this reason, the most recent directive on the energy performance of buildings (EPBD) is oriented towards improving the economic and environmental sustainability of buildings [2], also promoting the development of more efficient management strategies. In this perspective, it has to be considered that the global energy demand is currently increasing, especially in developing countries (in 2018 the growth rate of global energy demand was $2.3 \%$, the highest recorded in the last ten years [3]) and as discussed in [4], [5], an increase in the energy consumption in the building sector is, also, estimated. In this regard, an approach for designing buildings or upgrading the existing heritage, inspired by energy flexibility, can provide potential solutions [6]. This is evidenced by the research developed within the International Energy Agency (IEA) EBC Annex 67:

\footnotetext{
*Corresponding author: ilaria.marotta@deim.unipa.it
} 
"Energy Flexible Buildings". Energy flexibility is defined as: "The ability to manage demand and generation based on local climatic conditions, user needs and network requirements" [7].

One of the main approaches used to increase the energy flexibility of a building is the Demand Side Management (DSM). As discussed in [8-11], this is generally based on the modulation of the heating/cooling temperature set-point or other variables through the implementation of Rule Based Control (RBC), Model predictive control (MPC) and optimization strategies; or through the use of energy storage systems. The potential for flexibility can also grow, through the use of smart energy meters for smart grids, which allow the dissemination of price and production data for electricity imported from the grid $[12,13]$.

For example, Salom et al. [14] implement a RBC type algorithm for controlling the heating set-point. The input is a price signal consisting of periods of high and low penalty and obtained from the price data of the operator of the Spanish transmission system. The goal is to reduce the operating costs of an apartment in Barcelona. In [15] the same flexible control is tested but in order to reduce the $\mathrm{CO}_{2}$ emissions associated with the electrical uses of the building. In this case also the cooling set-point is controlled. Salom et al [16], use a MPC strategy using TRNSYS in combination with MATLAB. Three optimization problems are posed by varying the objective function, relating to the air-conditioning of the case study, to be optimized (energy cost, thermal demand and $\mathrm{CO}_{2}$ emissions). In [17,18], the effectiveness of a strategy is tested which provides for the application of fixed heating system ADR (Active Demand Response) events. In fact, these solutions always take place at a certain time and for a certain duration (e.g. from 8:00 for 4 hours). During ADR episodes, the heating set-point is increased or decreased by a fixed amount compared to the reference set-point value.

The aim of the paper is the analysis of a case study in southern Italy from the energy flexibility point of view, while investigating two different objectives: the reduction of costs for energy use and the reduction of $\mathrm{CO}_{2}$ emissions associated. The study is developed through building simulation of a real case-study and a wide development of parametric analyses on the control choices.

\section{Methodology}

The test-case is a residential building located in Southern Italy. Modeling and simulation are carried out in TRNSYS environment. The approach includes the development of a set of scenarios to improve the potential for energy flexibility within the building, both in relation to operating costs and in relation to the environmental impact of the building use phase.

\subsection{Building modeling}

The building is an isolated single family house, with an area of $631 \mathrm{~m}^{2}$ in Sicily. The external walls have a transmittance $U$ equal to $0.32 \mathrm{~W} /\left(\mathrm{m}^{2} \mathrm{~K}\right)$, while the $\mathrm{U}$ of the external roof and of the floor is, respectively, 0.53 and $0.88 \mathrm{~W} /\left(\mathrm{m}^{2} \mathrm{~K}\right)$. The glass openings have a $\mathrm{U}$ of 2.89 $\mathrm{W} /\left(\mathrm{m}^{2} \mathrm{~K}\right)$. Only the first floor, characterized by an average number of occupants of three, is air-conditioned. The area of the apartment is $145 \mathrm{~m}^{2}$, the aspect ratio $\frac{S}{V}$ is 0.79 , the total dispersing surface is $338.17 \mathrm{~m}^{2}$, while the window to wall ratio of the external envelope is $15 \%$. The apartment consists of two bathrooms, a corridor, a kitchen, a living room, a closet and two bedrooms. A thermal zone is defined for each room. Data on occupancy, use and lighting profiles were acquired in order to model realistically the behavior of the occupants. Natural ventilation has been modeled, according to the Wind and Stack with Open Area method $[19,20]$. An air-to-air heat pump system is used for air conditioning, which is inactive between 1 am and 8:30 am and is active when there is at least one occupant at home during the day. The heating and cooling ideal loads systems work with temperature set-points of 22 
and $26^{\circ} \mathrm{C}$, the internal air temperature is assumed to be equal to the set-point when the plant is active. The domestic hot water requirement is met by a natural gas boiler. The thermophysical simulations of the base case and the flexibility scenarios are carried out in TRNSYS, for the duration of one year and with a half-hour time-step.

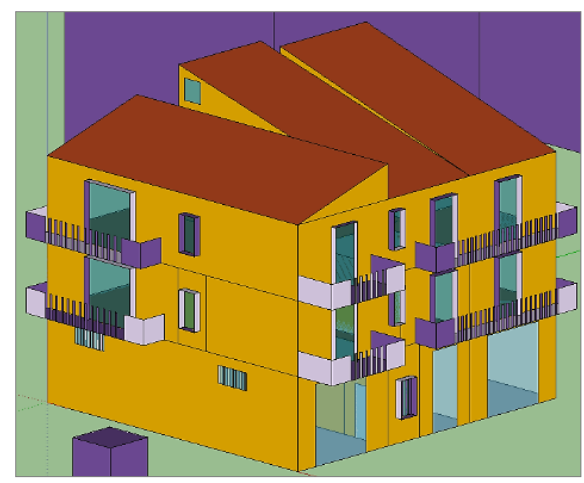

Fig. 1. Building model

\subsection{Energy flexibility scenarios}

To increase the energy flexibility of the case-study, exploiting its potential, Rule Based Control (RBC)-type algorithms are implemented. The guiding criteria of the research studies are costs $/ \mathrm{CO}_{2}$ emissions reduction. The controlled variable is the space heating $(\mathrm{SH})$ setpoint. The flexible control responds to a price or emission signal it receives at the input, identifying the corresponding hours in periods of high and low penalty (e.g. high cost and low cost). In parallel, it modulates the SH set-point according to its operating logic.

In general, in most research on flexibility the common factor is the effort in determining the shift of the load from the periods of high penalty (hp) to those of low penalty (lp). To characterize the distribution of the demand in the hp and lp periods, the Flexibility Factor (FF), described in Tab. 1, is used. FF is calculated as the difference between the energy required during the lp periods and that during the hp periods, divided by the total energy demand. FF varies in the range [+1-1]. A value of -1 means that the all energy use occurs in times of $h p$, vice versa a value of +1 indicates that it occurs in the lp periods.

Table 1. Flexibility Factors

\begin{tabular}{|c|c|c|}
\hline Flexibility Factor & Equation & Ref. \\
\hline FF (Costs) & $F F=\frac{L_{l p}-L_{h p}}{L_{l p}+L_{h p}}$ & {$[21]$} \\
\hline FF (Emissions) & $F F=\frac{\int_{l p} P_{e l} d t-\int_{h p} P_{e l} d t}{\int_{l p} P_{e l} d t+\int_{h p} P_{e l} d t}$ & {$[16]$} \\
\hline
\end{tabular}

\subsubsection{Economic RBC algorithm}

This section describes the method used to investigate the potential reduction of the costs associated with the electrical uses of the building. The study is divided into two energy flexibility analyses, as the conditions surrounding the purchase of electricity from the grid are changed. Specifically, two cases are examined:

1. The case where users benefit from a flat electricity price tariff. In this context, the bi-hourly tariff currently in use in the home is used.

2. The case of a dynamic electricity pricing, based on the trend of market prices. 
Flexible control of the SH set-point $\left(\mathrm{T}_{\mathrm{SH}}\right)$, could cause significant changes in thermal comfort compared to the basic scenario in which the $\mathrm{SH}$ set-point is $22{ }^{\circ} \mathrm{C}$. Therefore, in order to keep the temperature variations within an acceptable range, the maximum deviation from the reference is in absolute value equal to $2{ }^{\circ} \mathrm{C}$ [17]. Different $\mathrm{SH}$ set-point control logics are tested and their description is provided in Tab. 2.

Table 2. Control logics

\begin{tabular}{|c|c|l|}
\hline Case & Logic & \\
\hline a & $+\mathbf{1}$ & Increase of $\mathrm{T}_{\mathrm{SH}}$ by $1{ }^{\circ} \mathrm{C}$ in the lp periods \\
\hline b & $+\mathbf{2}$ & Increase of TSH by $2{ }^{\circ} \mathrm{C}$ in the lp periods \\
\hline c & $\mathbf{- 1}$ & Decrease of $\mathrm{T}_{\mathrm{SH}}$ by $1{ }^{\circ} \mathrm{C}$ in the hp periods \\
\hline d & $\mathbf{- 2}$ & Decrease of $\mathrm{T}_{\mathrm{SH}}$ by $2{ }^{\circ} \mathrm{C}$ in the hp periods \\
\hline e & $\mathbf{+ 1 - 1}$ & Decrease of $\mathrm{T}_{\mathrm{SH}}$ by $1{ }^{\circ} \mathrm{C}$ in the hp periods and increase by $1{ }^{\circ} \mathrm{C}$ in the lp periods \\
\hline f & $\mathbf{+ 1 - 2}$ & Decrease of $\mathrm{T}_{\mathrm{SH}}$ by $2{ }^{\circ} \mathrm{C}$ in the hp periods and increase by $1{ }^{\circ} \mathrm{C}$ in the lp periods \\
\hline g & $\mathbf{+ 2 - 2}$ & Decrease of $\mathrm{T}_{\mathrm{SH}}$ by $2{ }^{\circ} \mathrm{C}$ in the hp periods and increase by $2{ }^{\circ} \mathrm{C}$ in the lp periods \\
\hline h & $\mathbf{+ 2 - 1}$ & Decrease of $\mathrm{T}_{\mathrm{SH}}$ by $1{ }^{\circ} \mathrm{C}$ in the hp periods and increase by $2{ }^{\circ} \mathrm{C}$ in the lp periods \\
\hline
\end{tabular}

The results are shown in terms of economic saving and reduction of the $\mathrm{CO}_{2}$ emissions achieved and evolution of the Flexibility Factor (FF).

\subsubsection{Bi-hourly rate}

The bi-hourly rate negotiated with the market operator consists of two time slots F1 (8:0019:00) and F23 (19:00-8:00) [22]. The P1 and P23 prices are, respectively, 0.075 and 0.055 $€ / \mathrm{kWh}$. The high penalty periods are the F1 time slots; vice versa the time slots F23.

\subsubsection{Variable price rate}

The hourly electricity price data deriving from the market outcomes (for the Sicilian electricity area), disclosed by the Italian electricity market manager (GME), are used [23]. The identification of the high and low price periods occurs through the use of two variable thresholds. The low and high price thresholds are, respectively, defined as the $40^{\text {th }}$ and $60^{\text {th }}$ percentiles of the resulting price values for the day preceding that to which the thresholds refer $[14,15]$. An hour with a price value below the low price threshold (average value: 0.055 $€ / \mathrm{kWh}$ ) is classified as a lp period. Vice versa, hp periods occur when the price exceeds the high price threshold (average value: $0.065 € / \mathrm{kWh}$ ).

\subsubsection{Environmental RBC algorithm}

This section describes the method adopted in order to reduce the $\mathrm{CO}_{2}$ emissions associated with satisfying the electricity demand of the case-study by importing from the grid. The objective of the environmental control algorithm is to move the loads from the periods of high emissions (high penalty) to those of low emissions (low penalty) on the electricity grid. Also in this case, a trade-off analysis was carried out when the control logic changed, considering the alterations summarized in Tab. 2. The data used are GME data relating to the production technology of the Sicilian electric mix, which generates electricity at each hour of the year and feeds it into the grid. For the determination of a resulting emission profile the emission factors $\left(\mathrm{g} \mathrm{CO}_{2} / \mathrm{kWh}\right)$ of each production technology are used [24-26]. A threshold is used to make the lp periods constitute all the hours in which the energy is produced by RES, while the remaining hours are identified as hp periods. 


\section{Results}

The results of the scenarios analyzed are presented below.

\subsection{Basic configuration of the case-study}

The resulting annual electricity consumption is $3,196.33 \mathrm{kWh} / \mathrm{y}$ and the gas requirement is $256 \mathrm{~m}^{3} / \mathrm{y}$. The $\mathrm{FF}$ (Costs) is equal to -0.50 and 0.26 , respectively in the case of variable rate and bi-hourly rate. While FF (emissions) is equal to -0.73 . Therefore, electricity consumption occurs mainly in periods of high penalty, except in relation to costs with the F1-F23 tariff. However, in any case, there is room for improvement in terms of energy flexibility that should be investigated. The electricity demand for heating is equal to $46.79 \%$ of the total. Therefore, with a view to improving the economic-environmental performance of the testcase, it is important to intervene through specific measures on it.

\subsection{Case-study flexibility scenarios}

\subsubsection{Economic RBC algorithm}

This section reports the results achieved through the implementation of an RBC control algorithm of the SH set-point based on the cost reduction criterion for the two forms of pricing examined.

\subsubsection{Bi-hourly rate}

Fig. 2 describes, for some days of the winter season and for one thermal zone taken as example, the effect of applying the RBC algorithm operating according to Scenario d. The downward modulation of the SH set-point, in the higher-priced time slot, means that the trend of the thermal power required for space heating in the F23 periods dominates the reference trend. In fact, during the first day and with respect to the base case, the thermal energy requirement during the F23 period increases by $77.66 \%$ and the surplus is equal to $1.55 \mathrm{kWh}$. The demand for thermal energy during the F1 period is reduced, instead, by $51.30 \%$, that is by $4.20 \mathrm{kWh}$.

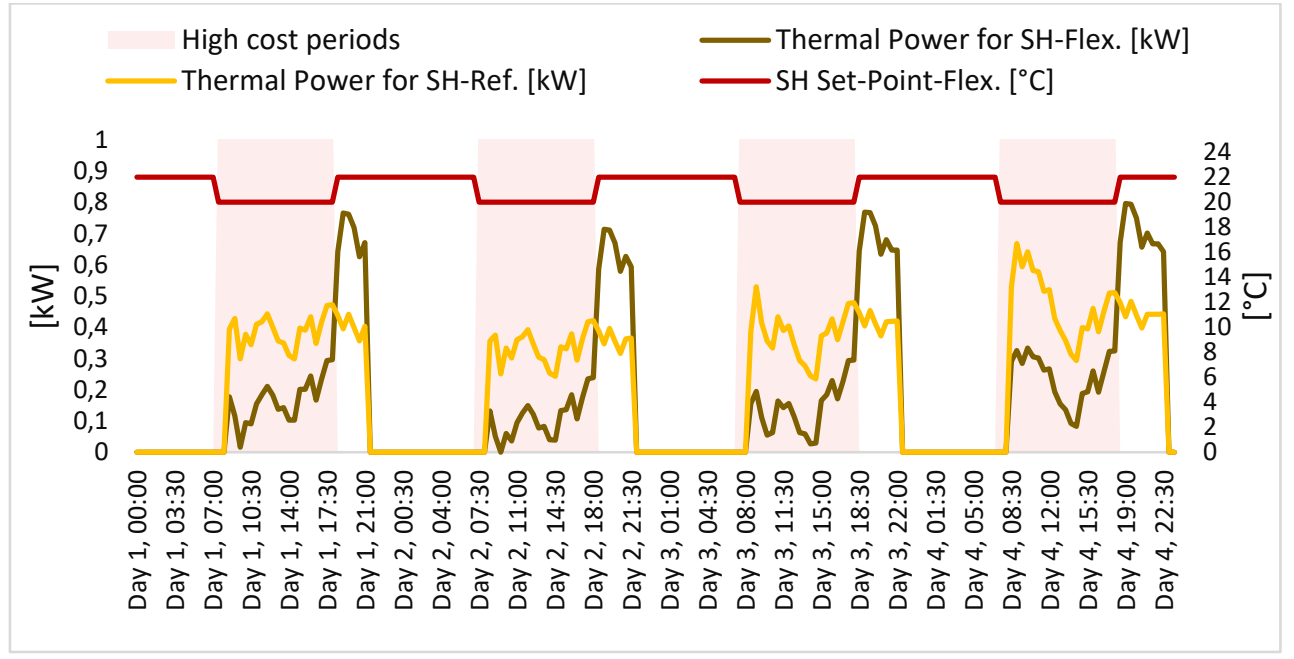

Fig. 2. Operation of the SH system of the zone 1 for some typical winter days (-2 control logic) 


\subsubsection{Variable price rate}

The variations induced by the flexibility strategy, in terms of variation of the electricity demand profiles for $\mathrm{SH}$, are shown in Fig. 3 with reference to the +2 control logic. The figure describes, for the thermal zone 2, the functioning of the heating system for the same typical days considered in section 4.3.1.1. The application of the strategy causes a reduction of energy needs for SH during periods of high price. For example, for day 1, it is $1.40 \mathrm{kWh}$; equal to $39 \%$ of the reference value. On the other hand, the heat energy requirement during the lp periods increases by $2.65 \mathrm{kWh}$. The implementation of the control logic, therefore, causes the shift of the load from the periods of high penalty to those of low penalty.

Fig. 4 shows an example of control that operates by decreasing the set-point during high price hours. Compared to the reference, this action causes an increase in the energy requirement for $\mathrm{SH}$ (rebound effect) during the lp periods of $9.16 \%$ and equal to $0.41 \mathrm{kWh}$. The energy demand during the high price period is reduced by $30.31 \%$ and the energy deficit is $1.72 \mathrm{kWh}$. The daily peak increases by $0.03 \mathrm{kWh}$, i.e. by $7 \%$.

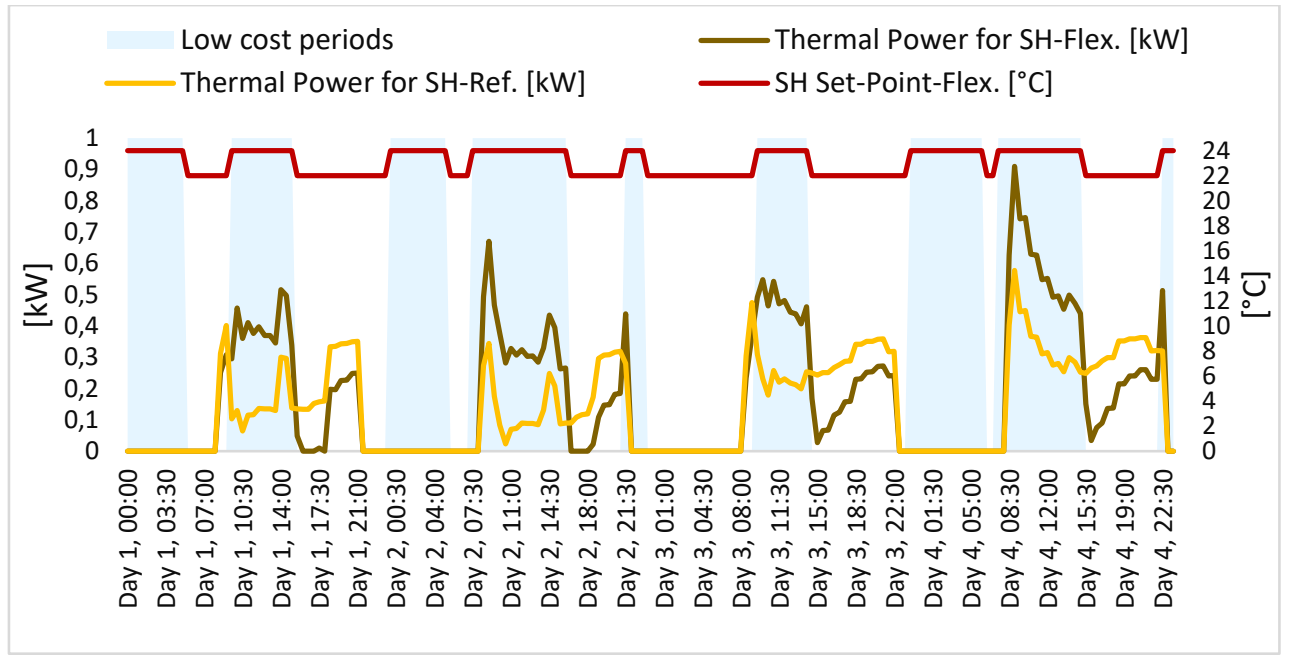

Fig. 3. Operation of the SH system of the zone 2 for some typical winter days $(+2$ control logic $)$

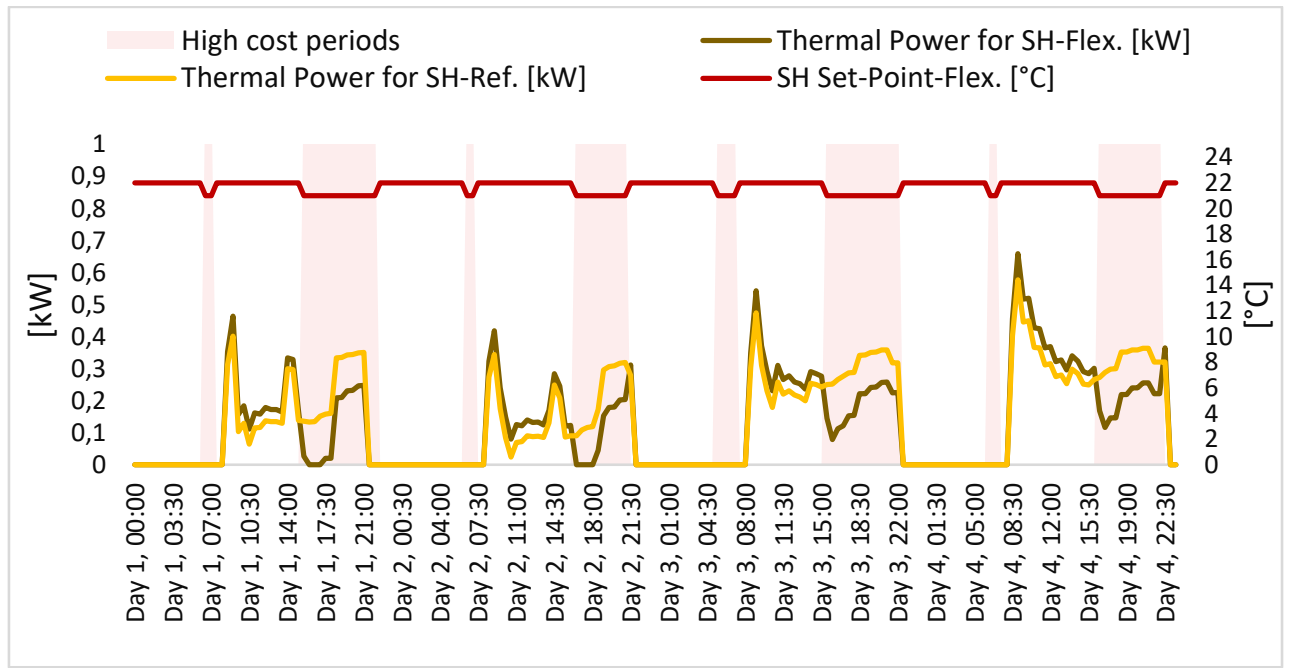

Fig. 4. Operation of the SH system of the zone 1 for some typical winter days (-1 control logic) 


\subsubsection{Comparison of results}

For each pricing scenario, the results of the sensitivity analysis performed when the control logic of the RBC algorithm changes, are summarized in Tab. 3 and in Fig. 5. In the case of scenario $\mathrm{h}$, applied taking into account dynamic pricing, there is an economic saving of $9.41 \%$, although in this scenario there is an annual electricity consumption value of 3249.48 $\mathrm{kWh}$, higher than the reference value of $1,6 \%$. This underlines the difference between energy saving and energy flexibility measures. Scenario a and b, based on increasing the SH setpoint during lp periods are not effective in both pricing cases. In the case of variable electricity prices, the best performing scenarios are those which envisage the implementation of a RBC algorithm which operates either by decreasing by $2{ }^{\circ} \mathrm{C}$ in high cost periods and increasing by $1{ }^{\circ} \mathrm{C}$ during low-cost ones, or following the rule -2 . In the latter case, an economic saving of $21.46 \%$ is obtained, accompanied by a $15 \%$ reduction in emissions. The most effective, in the case of bi-hourly rate, occurs when the -2 rule is used. This leads to an economic saving of $13.56 \%$ and a reduction in emissions of $8.5 \%$.

Table 3. Values of Flexibility Factor (Costs)

\begin{tabular}{|c|c|c|c|c|c|c|c|c|}
\hline Scenario & a & b & c & d & e & f & g & h \\
\hline FF-Variable price rate & -0.49 & -0.24 & -0.40 & -0.30 & -0.27 & -0.18 & -0.04 & -0.22 \\
\hline FF-Bi-hourly rate & -0.15 & 0.17 & 0.01 & 0.13 & 0.15 & 0.25 & 0.35 & 0.28 \\
\hline
\end{tabular}

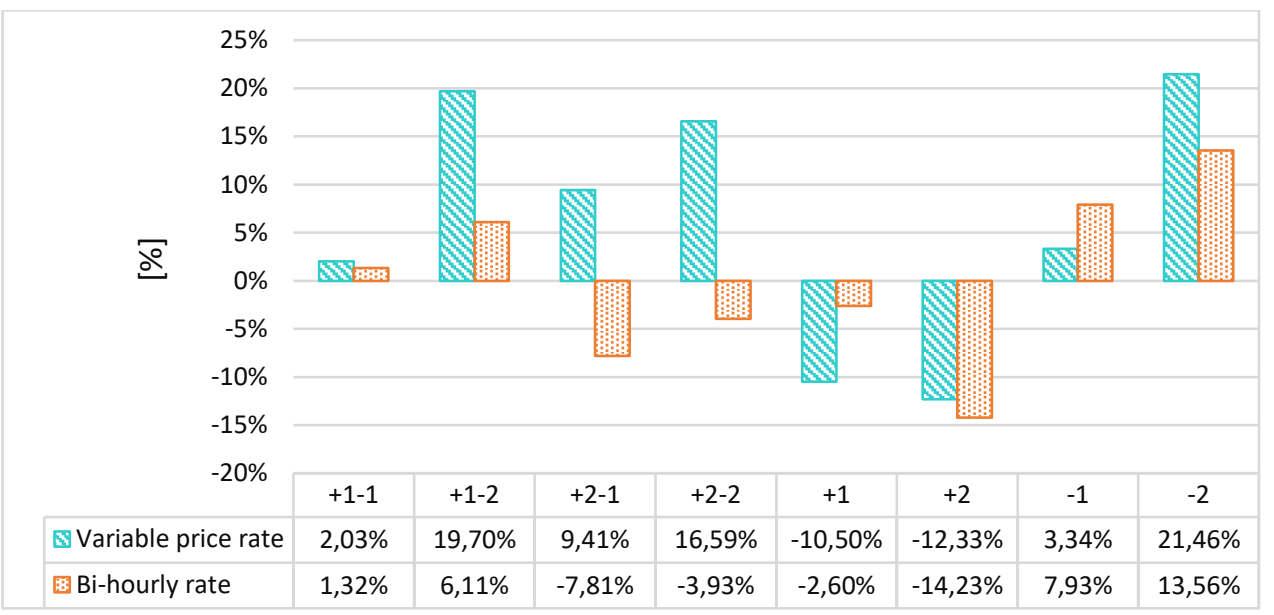

Fig. 5. Percentage value of economic savings

\subsubsection{Environmental RBC algorithm}

This section presents the results obtained by testing the RBC control algorithm aimed at reducing $\mathrm{CO}_{2}$ emissions related to the import of electricity from the grid. The profile of energy demand for heating is modified, with respect to that of the base-case, responding to the external emission signal. In this context, an example is shown in Fig. 6, for Zone 3 and the control logic $+1-1$.

The results of the sensitivity analysis carried out when the control logic changes, are expressed in Tab. 4. The best scenario corresponds to the $+2-2$ rule. In this scenario, together with the $30.23 \%$ reduction in $\mathrm{CO}_{2}$ emissions, there is an economic saving of $17.58 \%$ in the case of dynamic prices. The energy consumption of the building decreases by approximately $11 \%$, while FF improves compared to the reference value. 


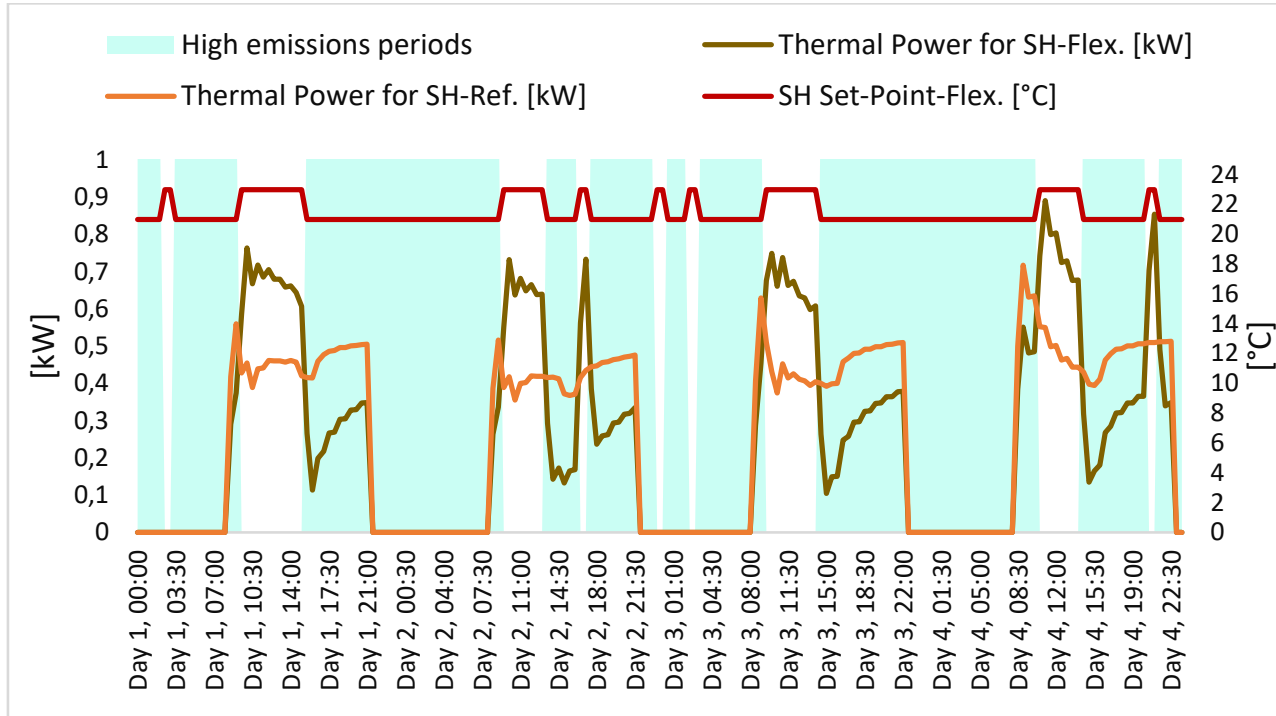

Fig. 6. Operation of the SH system of the Zone 3 for some typical winter days (+1-1 control logic)

Table 4. Results of the Environmental RBC algorithm

\begin{tabular}{|c|c|c|c|c|c|c|c|c|}
\hline Scenario & a & b & c & d & e & f & g & h \\
\hline $\begin{array}{c}\text { Emissions } \\
\text { reduction }\end{array}$ & $2.79 \%$ & $5.62 \%$ & $14.80 \%$ & $26.72 \%$ & $17.18 \%$ & $28.59 \%$ & $30.23 \%$ & $19.46 \%$ \\
\hline $\begin{array}{c}\text { FF } \\
\text { (emissions) }\end{array}$ & -0.64 & -0.54 & -0.65 & -0.57 & -0.55 & -0.47 & -0.36 & -0.45 \\
\hline
\end{tabular}

\section{Discussion and conclusions}

The potential for energy flexibility of a Mediterranean case-study was investigated in this paper, with reference to the flexible control of the space heating system. In this context, a twofold flexibility analysis was carried out as the guiding criterion changed (cost reduction and $\mathrm{CO}_{2}$ emissions reduction) and the boundary conditions (flat or dynamic electricity pricing). The study reveals the effectiveness of the use of RBC type algorithms, both from an environmental and economic point of view. The chosen environmental inspired approach achieves a reduction of $\mathrm{CO}_{2}$ emissions of approximately $30 \%$ if compared to the base case. At the same time, FF (Emissions) increases by $50 \%$. The economic impact is positive, with a $17.58 \%$ reduction in costs. In the case of variable electricity pricing, the RBC algorithm which aims to reduce costs, in the best scenario, achieves a $21.46 \%$ reduction in costs. At the same time, there is a $15 \%$ reduction in emissions and a change in FF (Costs) of $40 \%$. In the case of a bi-hourly rate the flexible control allows an economic saving of $13.56 \%$, accompanied by a reduction in emissions of $8.5 \%$. FF (Costs) varies by -0.14 to 0.13 . Higher margins of energy flexibility can be activated, in the case of the dynamic electricity tariff, compared to a flat tariff such as the bi-hourly one. The study highlights the potential of flexibility strategies in Southern Italy and in similar contexts. Therefore, it is important to promote an approach to designing new buildings or renovating existing ones, which considers energy flexibility as one of the central elements of the project. In this context, designers, endusers and policy makers should move towards a new way of building and managing urban agglomerations, focused on the energy flexibility of buildings. 


\section{References}

1. International Energy Agency, UN Environment Programme, Global Alliance for Buildings and Construction, International Energy Agency and the United Nations Environment Programme (2019): 2019 global status report for buildings and construction: Towards a zero-emission, efficient and resilient buildings and const, 2019.

https://webstore.iea.org/download/direct/2930?filename=2019_global_status_report _for_buildings_and_construction.pdf.

2. $\overline{\text { E. }}$ (2018) Recast, DIRECTIVE (EU) 2018/844 OF THE EUROPEAN PARLIAMENT AND OF THE COUNCIL of 30 May 2018 amending Directive 2010/31/EU on the energy performance of buildings and Directive 2012/27/EU on energy efficiency (Text with EEA relevance), n.d.

3. Global Energy \& CO2 Status Report 2018 - Analysis - IEA, (n.d.). https://www.iea.org/reports/global-energy-co2-status-report-2018 (accessed December 9, 2019).

4. M. Cellura, F. Guarino, S. Longo, M. Mistretta, A. Orioli, The role of the building sector for reducing energy consumption and greenhouse gases: An Italian case study, Renew. Energy. 60 (2013) 586-597. https://doi.org/10.1016/j.renene.2013.06.019.

5. M. Cellura, A. Di Gangi, S. Longo, A. Orioli, An Italian input-output model for the assessment of energy and environmental benefits arising from retrofit actions of buildings, Energy $\quad$ Build. 62 (2013) 97-106. https://doi.org/10.1016/j.enbuild.2013.02.056.

6. N. O'Connell, P. Pinson, H. Madsen, M. O'Malley, Benefits and challenges of electrical demand response: A critical review, Renew. Sustain. Energy Rev. 39 (2014) 686-699. https://doi.org/10.1016/J.RSER.2014.07.098.

7. B. Initiatives, Position Paper of the IEA Energy in Buildings and Communities Program (EBC) Annex 67 "Energy Flexible Buildings," (2017) 1-16. http://www.annex67.org.

8. C. Finck, P. Beagon, J. Clau $\{\backslash s s\}$, P. Thibault, P.J.C. Vogler-Finck, K. Zhang, H. Kazmi, Review of applied and tested control possibilities for energy flexibility in buildings: a technical report from IEA EBC Annex 67 Energy Flexible Buildings, (2017) 1-59. https://doi.org/10.13140/RG.2.2.28740.73609.

9. J. Clauß, C. Finck, P. Vogler-finck, P. Beagon, Control strategies for building energy systems to unlock demand side flexibility - A review Norwegian University of Science and Technology, Trondheim, Norway Eindhoven University of Technology , Eindhoven, Netherlands Neogrid Technologies ApS / Aalborg, 15th Int. Conf. Int. Build. Perform. (2017) 611-620.

10. Y. Chen, P. Xu, J. Gu, F. Schmidt, W. Li, Measures to improve energy demand flexibility in buildings for demand response (DR): A review, Energy Build. 177 (2018) 125-139. https://doi.org/10.1016/j.enbuild.2018.08.003.

11. I.E. Agency., IEA EBC Annex 67 Energy Flexible Buildings, (n.d.).

12. I. Vassileva, J. Campillo, Consumers' Perspective on Full-Scale Adoption of Smart Meters: A Case Study in Västerås, Sweden, Resources. 5 (2016) 3. https://doi.org/10.3390/resources5010003.

13. S. Gottwalt, W. Ketter, C. Block, J. Collins, C. Weinhardt, Demand side management-A simulation of household behavior under variable prices, Energy Policy. 39 (2011) 8163-8174. https://doi.org/10.1016/J.ENPOL.2011.10.016.

14. T.Q. Péan, J. Salom, J. Ortiz, Potential and optimization of a price-based control strategy for improving energy flexibility in Mediterranean buildings, Energy Procedia. 122 (2017) 463-468. https://doi.org/10.1016/j.egypro.2017.07.292. 
15. T. Péan, J. Salom, J. Ortiz, Environmental and Economic Impact of Demand Response Strategies for Energy Flexible Buildings, Build. Simul. Optim. BSO 2018, 11-12th Sept. 2018, Cambridge. (2018) 277-283.

16. T. Péan, R. Costa-Castelló, J. Salom, Price and carbon-based energy flexibility of residential heating and cooling loads using model predictive control, Sustain. Cities Soc. 50 (2019) 101579. https://doi.org/10.1016/J.SCS.2019.101579.

17. K. Foteinaki, R. Li, A. Heller, C. Rode, Heating system energy flexibility of lowenergy residential buildings, Energy Build. $180 \quad$ (2018) 95-108. https://doi.org/10.1016/j.enbuild.2018.09.030.

18. G. Reynders, R. Amaral Lopes, A. Marszal-Pomianowska, D. Aelenei, J. Martins, D. Saelens, Energy flexible buildings: An evaluation of definitions and quantification methodologies applied to thermal storage, Energy Build. 166 (2018) 372-390. https://doi.org/10.1016/j.enbuild.2018.02.040.

19. DOE, Engineering Reference of EnergyPlus, (2017) 1-1704.

20. ASHRAE, Inc. 2009 ASHRAE handbook: fundamentals. American Society of Heating, Refrigeration and Air-Conditioning Engineers, (2009).

21. J. Le Dréau, P. Heiselberg, Energy flexibility of residential buildings using short term heat storage in the thermal mass, Energy. 111 (2016) 991-1002. https://doi.org/10.1016/j.energy.2016.05.076.

22. ENEL, https://www.enel.it/it/luce-e-gas/luce/offerte/e-light-bioraria, (n.d.).

23. GME - Gestore dei Mercati Energetici, Esiti dei mercati - MGP - esiti, (n.d.). https://www.mercatoelettrico.org/it/Esiti/MGP/EsitiMGP.aspx.

24. R. 303/2019 ISPRA, Fattori di emissione atmosferica di gas a effetto serra nel settore elettrico nazionale e nei principali Paesi Europei, 2019.

25. Intergovernmental Panel on Climate Change, Intergovernmental Panel on Climate Change, Technology-specific Cost and Performance Parameters, Clim. Chang. 2014 $\begin{array}{llll}\text { Mitig. } & \text { Clim. } & \text { Chang. } & \text { (2015) }\end{array}$ https://doi.org/10.1017/cbo9781107415416.025.

26. M. Cellura, M.A. Cusenza, S. Longo, Energy-related GHG emissions balances: IPCC versus LCA, Sci. Total Environ. 628-629 (2018) 1328-1339. https://doi.org/10.1016/j.scitotenv.2018.02.145. 